\title{
ASSESSING THE VISIBILITY OF RAISED PAVEMENT MARKERS AND ALTERNATIVE FORMS OF DELINEATION
}

\author{
John D. BULLOUGH ${ }^{1^{* \#}}$, Xiang LIU ${ }^{2}$ \\ ${ }^{1}$ Lighting Research Center, Rensselaer Polytechnic Institute, United States \\ ${ }^{2}$ Dept of Civil and Environmental Engineering, Rutgers University, United States
}

Received 1 March 2018; revised 18 December 2018; accepted 1 March 2019

\begin{abstract}
Raised Pavement Markers (RPMs) are used by a number of transportation agencies with the objective of improving roadway safety, especially in complex roadway geometries and along wet roads. Because of maintenance and cost issues, many transportation agencies are exploring alternatives to RPMs such as wet reflective pavement tape and barrier-mounted reflective delineators. In order to assess the relative potential of these devices to contribute to nighttime driving safety, the luminances of new and used RPM samples from different manufacturers and having different colors and of several alternative delineation devices were measured in the laboratory using a range of geometric conditions relevant to the driving task. From these data, Luminances under representative low-beam headlight illumination were determined and these quantities were used to estimate driver visual performance. Large variations in luminance yielded relatively small differences in visual performance for a viewing distance of $100 \mathrm{~m}$, primarily because of the plateau characteristic of visual performance. Differences in threshold visibility distances were greater, with distances at identification threshold for the devices measured ranging approximately from 150 to $400 \mathrm{~m}$. Used RPMs had luminances $20 \ldots 30 \%$ lower than new RPMs but similar visibility characteristics as new devices. The analysis method in this study may be useful for practitioners seeking to characterize the visual effectiveness of RPMs and other roadway delineation devices and systems.
\end{abstract}

Keywords: visual performance, pavement markings, roadway delineators, visibility distance, retroreflectivity.

\section{Introduction}

Raised Pavement Markers (RPMs) are used by a number of transportation agencies with the objective of improving roadway safety. When roadway curvature impairs the visibility of conventional pavement markings, RPMs are thought to provide additional visual guidance that can provide drivers with extended preview time about the roadway geometry, lane width and other visual cues. RPMs also provide improved visibility in wet weather because with these devices, the visible or reflective element is raised above the level of water on the pavement surface (Lay 2009). Because of maintenance issues and costs associated with RPMs (Bahar et al. 2004), transportation agencies have also investigated alternative delineation devices and systems, including wet reflective pavement marking tape and barrier-mounted reflective delineators.

\section{Literature review}

Several studies of the impacts of RPMs on driving behavior and on traffic safety have been performed. For example, Niessner (1984), Krammes and Tyer (1991), Hammond and Wegmann (2001) found a reduction in encroachments into opposing lanes was associated with the installation of RPMs. Effects on vehicle speed, in comparison, have been mixed (Niessner 1984; Zador et al. 1987) and likely interact with roadway geometry. With respect to traffic safety, results also appear to be mixed (Zador et al. 1982; Griffin 1989; NYSDOT 1997; Bahar et al. 2004). Bahar et al. (2004) reported that crashes in locations with higher traffic volumes and occurring at night during wet weather conditions were more likely to be reduced than other situations. Lyon et al. (2015) evaluated safety impacts of wet reflective pavement markings, and found they were associated with fewer crashes. Haas (2004) reported that vehicle speeds tended to be reduced in work zones following the installation of barrier-mounted reflective delineators; reduced speeds were thought to contribute to increased safety.

Relatively few safety evaluations of RPMs have been conducted within the past five years. More recently, Liang

${ }^{*}$ Corresponding author. E-mail: bulloj@rpi.edu

\#Editor of the TRANSPORT - the manuscript was handled by one of the Associate Editors, who made all decisions related to the manuscript (including the choice of referees and the ultimate decision on the revision and publishing). 
et al. (2018) investigated the potential effect of angling RPMs toward oncoming drivers on visibility, but found this would make little difference. Lu et al. (2016) suggested several geometric modifications to the shape of RPMs to increase their durability when vehicles drive over them, but this study did not assess visibility.

Cautiously accepting the tentative conclusions of $\mathrm{Ba}-$ har et al. (2004), Lyon et al. (2015) and Haas (2004) that RPMs can benefit safety, the present paper describes efforts to characterize RPMs and alternatives to RPMs in terms of their luminances when exposed to headlight illumination and subsequently in terms of their visibility using the Relative Visual Performance (RVP) model (Rea, Ouellette 1991). Visual performance analyses are used in this study because unlike some road safety systems such as rumble strips using tactile information, the benefit of RPMs is through their visual information. The RVP model characterizes the speed and accuracy of visual processing as a function of luminance, contrast, and size of a visual target for an observer of a particular age.

RVP quantities range from zero at the threshold of visual identification to values greater than one; a value of one corresponds to a reference visibility condition similar to reading large, high-contrast printed text under office lighting levels. Values higher than one are possible, but once an RVP value from 0.8 to 0.9 is reached, further increases in light level, contrast or size are unlikely to have substantial impacts on visual speed and accuracy, because visual performance exhibits a "plateau" response, with diminishing returns once a visual target is on the plateau (e.g., doubling the luminance of an object will not double its visibility; it may even have a negligible impact on visibility, if visibility is already high). Equations for calculating RVP have been published by Rea and Ouellette (1991) and by Bullough et al. (2008).

The plateau characteristic of visual performance is an important impetus for determining not only the photometric and retroreflective performance of RPMs and other devices, such as measurements recently reported by Pike (2017), but also to identify how light level, viewing distance and device performance interact to provide a useful visual stimulus to drivers approaching them.

The RVP model has been shown to be strongly correlated to psychophysical measures such as response times, detection distances and legibility of signs and symbols in the roadway driving context (Bullough, Radetsky 2014). Further, Bullough et al. (2013) have shown strong correlations between RVP improvements associated with roadway intersection lighting and nighttime crash reductions at intersections outfitted with lighting. These findings suggest the RVP model could have utility in assessing the visual effectiveness of RPMs and of alternatives to RPMs.

Study objective. A gap in the literature regarding the benefits of RPMs is how they compare to alternatives such as those described above. In order to address this knowledge gap about the visual effectiveness of RPMs and other devices as experienced by drivers under nighttime conditions, the objective of the present study was to use laboratory measurements and subsequent photometric and visibility analyses to evaluate not only the luminance but also the visual performance expected of specific RPMs and alternative devices under a representative range of geometric conditions under real-world situations. Doing so would help transportation agencies identify when and where RPMs and their alternatives may be most beneficial to driving safety, since their benefit is primarily visual.

\section{Methods}

The procedure used to measure the luminances of RPMs and their alternatives in the laboratory was not a formally standardized procedure such as that developed by ASTM D4383-18 for RPMs, using specialized instrumentation or specific viewing geometries; rather it was developed to assess luminance, retroreflectivity, and ultimately, visual performance for a range of geometric conditions that might be relevant to nighttime driving (i.e., vertical angles from straight ahead to $1^{\circ}$ down, and horizontal angles from $10^{\circ}$ left to $10^{\circ}$ right, to capture a range of roadway curvatures), and which could be used not only for RPMs but also with other types of delineation systems as well. New RPMs from three manufacturers (denoted A, B and C) were obtained including white, yellow, red and blue markers (not all colors were available from each manufacturer). Wet pavement reflective tape samples $(10 \mathrm{~cm}$ wide $\times 10 \mathrm{~cm}$ long) from one manufacturer were obtained in white and yellow colors. Barrier-mounted reflective delineators $(10 \mathrm{~cm}$ wide white, $6 \mathrm{~cm}$ wide yellow, $15 \mathrm{~cm}$ wide orange and $10 \mathrm{~cm}$ wide red) were also tested; each was $0.9 \mathrm{~m}$ in length. All of these devices were tested in good, new condition.

Two used yellow RPMs from one of the three manufacturers (B) that had been in service on highways in New Jersey were provided by the New Jersey Department of Transportation (NJDOT) in order to check the magnitude of any degradation in performance after use, compared to new RPMs of the same type and from the same manufacturer. The ages of the used RPMs were not known; they were scratched, dirty and had small portions of the retroreflective elements missing, but were not severely damaged.

RPMs (Figure 1) and wet reflective tape samples affixed to black painted plywood (Figure 2) were mounted onto a platform fastened to a tripod (Figure 3), and adjusted for height and orientation to be either $0^{\circ}$ or $1^{\circ}$ below the entrance optics of a handheld luminance meter (Minolta, LS-100), which was mounted onto another tripod $6 \mathrm{~m}$ away (Figure 4). The barrier-mounted reflective delineator samples (Figure 5) were attached to a $0.9 \mathrm{~m}$ long piece of plywood, which was mounted onto the tripod in a vertical orientation as these devices would be in practice. Because the barrier-mounted reflective delineator is intended to be mounted above ground level, only the $0^{\circ}$ vertical angles were used for these devices. 


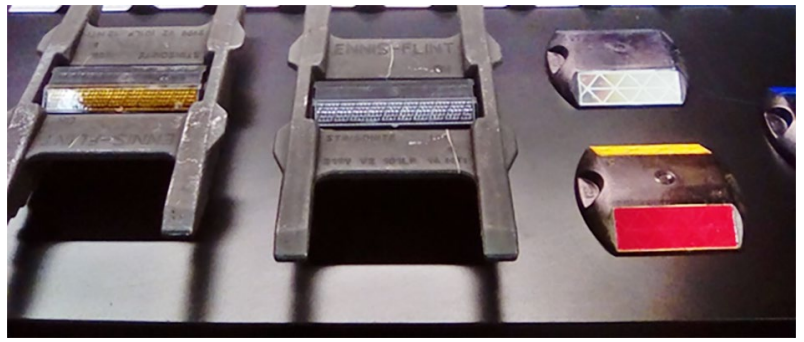

Figure 1. Examples of RPM samples
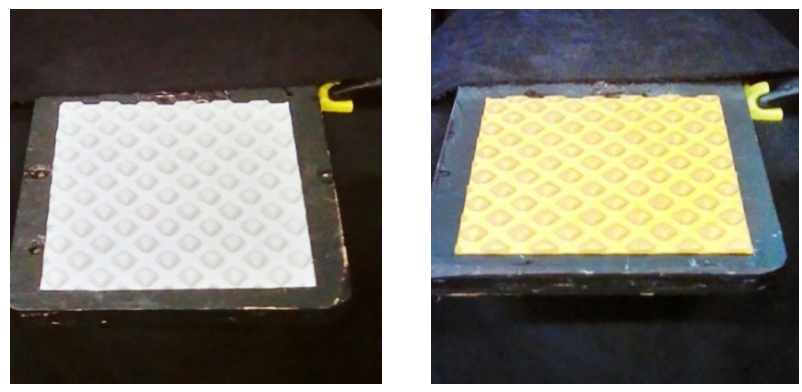

Figure 2. Examples of wet reflective pavement marking tape samples

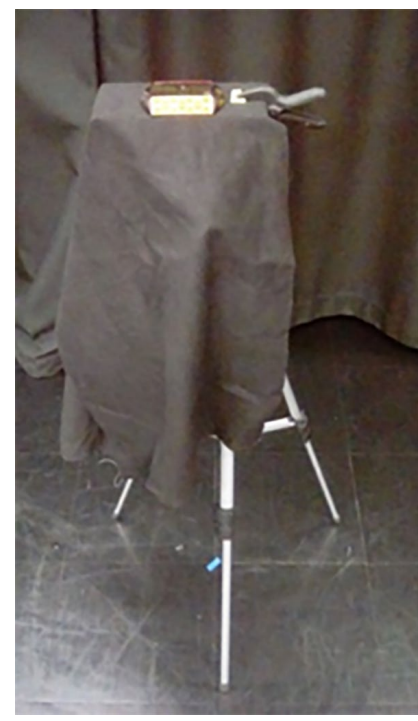

Figure 3. RPM measurement sample mounted on tripod platform

Also attached to the luminance meter (and shown in Figure 4) was a $40 \mathrm{~W}$ incandescent appliance lamp bulb, producing a spectral distribution very similar to Illuminant A specified by ASTM D4383-18, positioned $10 \mathrm{~cm}$ below the luminance meter's entrance optics (and located $1^{\circ}$ below from a distance of $6 \mathrm{~m}$, corresponding to an entrance angle of $1^{\circ}$ ). All laboratory measurements were made under dry conditions.

The measurement sample tripod could be moved to different lateral positions to be located directly ahead of the luminance meter $\left(0^{\circ}\right.$ horizontal angle), or $5^{\circ}$ or $10^{\circ}$ to either side (left or right) of the luminance meter (these angles approximated the observation angle for each condition). The height of the tripod could be set to match the
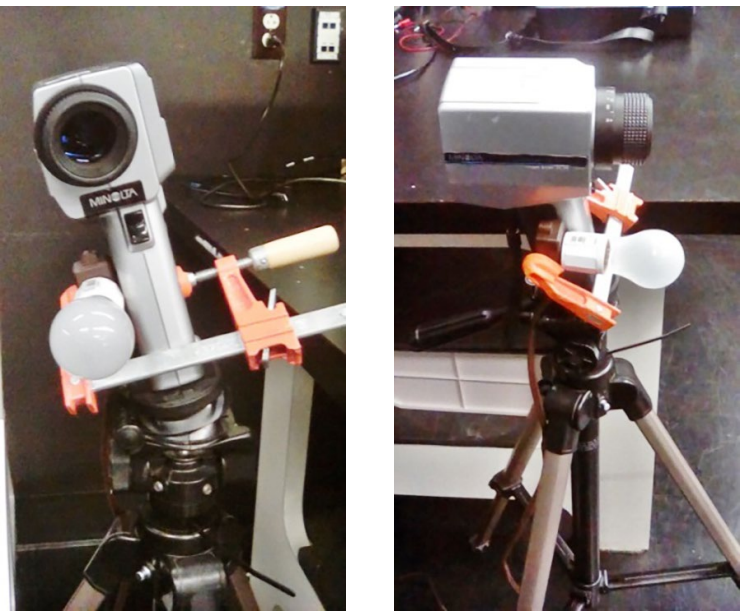

Figure 4. Luminance meter and light source (left: front view, right: side view)

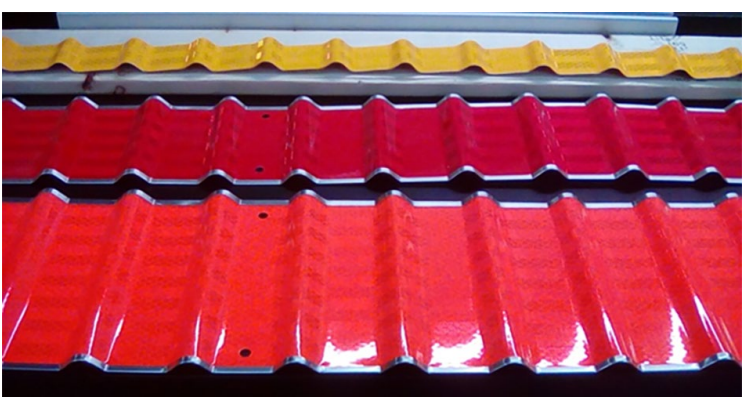

Figure 5. Examples of barrier-mounted reflective delineator samples

height of the luminance meter entrance optics or $10 \mathrm{~cm}$ below $\left(1^{\circ}\right.$ below the luminance meter entrance optics for the measurement distance of $6 \mathrm{~m}$, as illustrated in Figure 3). An angle of $1^{\circ}$ below the meter's entrance optics corresponds to a viewing distance of $83 \mathrm{~m}$ ahead of a vehicle (IES 2014), for a perfectly flat road. Some of the RPMs were mounted in steel casters, and portions of RPM housings that were constructed of light-colored material were colored with a black permanent magic marker to reduce measurement noise.

All measurements took place in a black-painted laboratory to minimize reflections from stray light. The calibrated luminance meter was used with a spot size large enough (i.e., $1^{\circ}$ ) to completely encompass the device from $6 \mathrm{~m}$ away. The device locations used are described graphically in Figure 6.

The $1^{\circ}$ range of vertical angles and $20^{\circ}$ range of horizontal angles corresponds to the representative ranges for pavement-mounted reflectors that could be encountered on roadway curves, and to the approximate angular region within which headlight intensity is highest (Bhise et al. 1977). With the light source energized, the luminance meter was used to capture the luminance of the $1^{\circ}$ viewing aperture centered around the marker or device $L_{a}\left[\mathrm{~cd} / \mathrm{m}^{2}\right]$. The projected angular area of a $1^{\circ}$ luminance spot is $0.785\left({ }^{\circ}\right)^{2}$. The projected angular area $A_{p}\left[\left(^{\circ}\right)^{2}\right]$ was calculated for the marker or device being measured. 


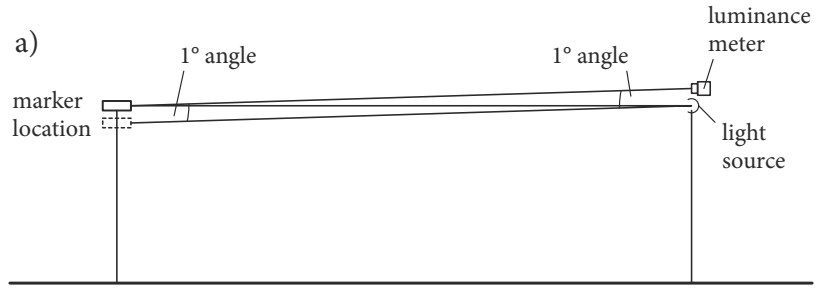

b)

\begin{tabular}{cccccc} 
vertical & \multicolumn{5}{c}{ horizontal angle } \\
\cline { 2 - 6 } angle & $-10^{\circ}$ & $-5^{\circ}$ & $0^{\circ}$ & $+5^{\circ}$ & $+10^{\circ}$ \\
\hline $0^{\circ}$ & & & & & \\
$1^{\circ}$ & & & & &
\end{tabular}

Figure 6. Plan view of measurement geometry showing the vertical measurement angles (a) and horizontal and vertical locations of the device being measured, viewed from the location of the light source (b) - negative horizontal angles correspond to those to the left of center (toward the driver side); positive horizontal angles correspond to those to the right of center (toward the passenger side)

Its luminance $L_{m}\left[\mathrm{~cd} / \mathrm{m}^{2}\right]$ could be calculated from the luminance spot measurement value using the following equation:

$$
L_{m}=L_{a} \cdot \frac{0.785}{A_{p}}
$$

The vertical illuminance $E[\mathrm{~lx}]$ from the light source at each location in Figure 6 was also measured. From these data, it was possible to calculate the coefficient of retroreflectivity $R_{c}\left[\mathrm{~cd} / \mathrm{l} \mathrm{x} / \mathrm{m}^{2}\right]$ for each angle (as a function of the vertical illuminance), using the following equation:

$$
R_{c}=\frac{L_{m}}{E} .
$$

This quantity is independent of the amount of illumination falling on the device at any particular location, because the coefficient of retroreflectivity is defined as the ratio of its luminance for a given vertical illuminance. If the vertical illuminance were doubled, the device luminance would also be doubled, but the ratio between these quantities would remain the same.

Finally, to estimate what the luminance of the device would be in a representative roadway scenario $L_{r s}\left[\mathrm{~cd} / \mathrm{m}^{2}\right]$ - under low beam headlamps at a given distance $d[\mathrm{~m}]$, market-weighted headlamp intensity values $I$ [cd] (Table 1) from research by Schoettle et al. (2004) were applied to the corresponding angular location's coefficient of retroreflectivity using the following equation:

$$
L_{r s}=\frac{R_{c} \cdot I}{d^{2}}
$$

The data in Table 1 correspond to a pair of low beam headlights, assumed for this purpose to be co-located in the center front of an approaching vehicle. It can be seen in Table 1 that low beam headlights tend to produce more light at a vertical angle of $1^{\circ}$ down than they do at $0^{\circ}$. The amount of light at the horizontal angle of $+5^{\circ}$, which corresponds to one lane toward the passenger side of the vehicle $50 \mathrm{~m}$ ahead, is also larger than the amount of light at the horizontal angle of $-5^{\circ}$, one lane toward the driver side.

The roadway scenario luminances were used, along with the physical dimensions of the projected retroreflective portions of each device, and an estimated roadway background luminance of $0.1 \mathrm{~cd} / \mathrm{m}^{2}$ (He et al. 1997), in order to calculate RVP (Rea, Ouellette 1991) values for these situations under headlight illumination, from a distance of $100 \mathrm{~m}$ from the marker or device. A driver age of 60 years was assumed for all of the visual performance calculations; this age was used as a representative, older driver age. Drivers aged 60 years or younger include approximately three-quarters of the US driving population (FHWA 2011).

\section{RVP calculation}

This section of the paper describes the RVP calculation procedure (Rea, Ouellette 1991; Bullough et al. 2008) used to estimate the visibility of each of the samples in the present study. Let $A$ be the observer's age in years. Let $L_{b}$ be the background luminance $\left[\mathrm{cd} / \mathrm{m}^{2}\right]$ (assumed to be $0.1 \mathrm{~cd} / \mathrm{m}^{2}$ as described above). Let $C$ be the luminance contrast, defined by $C=\frac{\left|L_{r s}-L_{b}\right|}{L_{r s}}$. Let $S$ be the solid angular size of the target in microsteradians $[\mu \mathrm{sr}]$, calculated by:

$$
S=\frac{1000000 \cdot T}{d^{2}},
$$

where: $T$ is the projected area of the target $\left[\mathrm{m}^{2}\right] ; d$ is the viewing distance $[\mathrm{m}]$. Then, the pupil radius $P[\mathrm{~mm}]$ is calculated:

$$
P=2.39-1.22 \cdot \tanh \left(0.3 \cdot \log L_{b}\right) .
$$

The pupil size is calculated because it impacts the amount of light reaching the retina of the eye. Following this, the age-corrected retinal illuminance $E_{r}$ in trolands [Td] is calculated:

$$
E_{r}=\pi \cdot P^{2} \cdot L_{b} \cdot(1-0.017 \cdot(A-20)) .
$$

\begin{tabular}{|c|c|c|c|c|c|}
\hline \multirow{2}{*}{ Vertical angle } & \multicolumn{5}{|c|}{ Horizontal angle } \\
\hline & $-10^{\circ}$ & $-5^{\circ}$ & $0^{\circ}$ & $+5^{\circ}$ & $+10^{\circ}$ \\
\hline $0^{\circ}$ & $1346 \mathrm{~cd}$ & $2186 \mathrm{~cd}$ & $17660 \mathrm{~cd}$ & $9434 \mathrm{~cd}$ & $2240 \mathrm{~cd}$ \\
\hline $1^{\circ} \downarrow$ & $6124 \mathrm{~cd}$ & $10612 \mathrm{~cd}$ & $37804 \mathrm{~cd}$ & $19796 \mathrm{~cd}$ & $5602 \mathrm{~cd}$ \\
\hline
\end{tabular}

Equation (6) adjusts the retinal illuminance due to the fact that the lens in the eye grows in thickness and reduces

Table 1. Luminous intensities from a representative pair of low beam headlamps toward several angular locations 
in transmittance as individuals age. Next, five intermediate values $\left(x_{1}, x_{2}, x_{3}, x_{4}\right.$ and $\left.x_{5}\right)$ are calculated:

$$
\begin{aligned}
& x_{1}=\log (\tanh (20000 \cdot S)) ; \\
& x_{2}=\log \left(\log \left(\frac{10 \cdot E_{r}}{\pi}\right)\right) ; \\
& x_{3}=1+(0.0025 \cdot(A-20)) ; \\
& x_{4}=\log (\tanh (5000 \cdot S)) ; \\
& x_{5}=\log \left(\tanh \left(\frac{0.04 \cdot E_{r}}{\pi}\right)\right) .
\end{aligned}
$$

The terms in Equations (7) represent curve-fitting parameters in the subsequent calculation of threshold contrast and visual response times. The threshold luminance contrast $C_{t}$ is calculated as follows:

$C_{t}=x_{3} \cdot 10^{-1.36-0.18 \cdot x_{1}-0.81 \cdot x_{2}+0.23 \cdot x_{1}^{2}-0.077 \cdot x_{2}^{2}+0.17 \cdot x_{1} \cdot x_{2}}$.

The term $C_{t}$ represents the minimum contrast that can be detected. The half-saturation constant $K$ is calculated by:

$$
K=10^{-1.76-0.18 \cdot x_{4}-0.031 \cdot x_{5}+0.11 \cdot x_{4}^{2}+0.17 \cdot x_{5}^{2}+0.062 \cdot x_{4} \cdot x_{5}}
$$

The half-saturation constant is used to determine how far above threshold a particular target is. Once a target elicits a strong response (e.g., a short response time), further increases in luminance, contrast or size will not result in stronger responses. Next, the maximum response $R_{\max }$ is calculated as follows:

$$
R_{\max }=0.0002 \cdot \log \left(E_{r}\right)+0.0027 .
$$

The $R_{\max }$ term is used to estimate the minimum response time that can be achieved for a particular retinal illuminance. The visual response time $V$ [ms], is calculated as:

$$
V=\frac{\left(C-C_{t}\right)^{0.97}+K^{0.97}}{\left(C-C_{t}\right)^{0.97} \cdot R_{\max }} .
$$

The visual response time is an estimate of the average time needed to detect and signal a response to a visual target. Finally, the RVP value is calculated:

$$
R V P=1.42-\frac{V}{778.56} .
$$

As mentioned previously, $R V P$ is a unitless quantity ranging from zero at the threshold of visual identification to values of one or greater; a value of one corresponds to a large, high-contrast target viewed under high light levels.

\section{Results}

Table 2 illustrates, for a white RPM sample from Manufacturer $\mathrm{A}$, the calculations made to identify its luminance under the laboratory test conditions based on the sample's size and measured luminance aperture value (Equation (1)). Subsequent calculations in Table 2 estimate the coefficient of retroreflectivity for each of the geometric conditions that were measured (Equation (2)), and calculations of the luminance that it would be expected to have under low-beam headlamp illumination at night from $100 \mathrm{~m}$ away (Equation (3)). From these latter luminance values, visual performance analyses were performed (using Equations (4)-(12)) to estimate an RVP value for each device, in each geometric location. It can be seen in Table 2 that the resulting RVP values (ranging from 0.995 to 1.029) were relatively insensitive to large variations in the luminance of the device (ranging from 16.42 to $389.35 \mathrm{~cd} / \mathrm{m}^{2}$ ). This insensitivity is related to the plateau characteristic of visual performance (Rea, Ouellette 1991); large differences in luminance, provided the luminances contribute to visual performance at or near the plateau, elicit only small changes in RVP.

Because of this insensitivity, only data for the horizontal angle of $0^{\circ}$, and for the vertical angle of $1^{\circ}$ down (for RPMs and wet reflective pavement marking tape), or for the vertical angle of $0^{\circ}$ (for the barrier-mounted reflective delineators) are shown in Figures 7-9 for each device. Figure 7 shows coefficients of retroreflectivity $\left[\mathrm{cd} / \mathrm{l} / \mathrm{m}^{2}\right]$, Figure 8 shows the device luminances $\left[\mathrm{cd} / \mathrm{m}^{2}\right] 100 \mathrm{~m}$ ahead of low beam headlight illumination, and Figure 9 shows the corresponding RVP values for each device under these conditions.

As mentioned above in the discussion of Table 2, and as seen in the panels of Figures 9, the resulting RVP values for all of the devices (whether new or used) were very close to one (despite large variations in luminance shown in Figure 8), suggesting that they would all be highly visible from $100 \mathrm{~m}$ away under low beam headlight illumination for the geometric condition represented (i.e., straight ahead). In order to identify potential differences among the markers and devices that were measured, a further analysis was conducted to identify at what viewing distances each of the devices would begin to approach the threshold visual performance level corresponding to an RVP value of zero, the threshold of visual identification (Rea, Ouellette 1991). To accomplish this, viewing distances were increased in $1 \mathrm{~m}$ steps starting between $100 \mathrm{~m}$ and $400 \mathrm{~m}$, and RVP values were calculated using the same procedures as illustrated in Table 2 for each distance, in order to determine the distance at which the RVP dropped below zero, indicating the threshold viewing distance for each device. Longer viewing distances for pavement markings have been linked to improved maintenance of lane position and vehicle speed, potentially improving safety (Horberry et al. 2006).

As the viewing distance from the device increases, two factors will decrease its visibility. First, the luminance will decrease because the illumination from the headlights will fall off according to the inverse square law (Rea 2000); doubling the distance to the RPM results in reducing its luminance by a factor of four. Second, the apparent size of the RPM (i.e., the solid angle it subtends) will also decrease as the viewing distance increases (Rea 2000), proportionally to the square of the distance. Thus, the devices would appear dimmer and smaller for larger viewing distances. 
Table 2. Photometric/visual performance summary: white RPM sample (Manufacturer A)

\begin{tabular}{|c|c|c|c|c|c|}
\hline RPM A (white) & \multicolumn{5}{|c|}{ Projected area $\left[\left(^{\circ}\right)^{2}\right]: 0.068567$} \\
\hline Measured illuminance $[\mathrm{lx}]$ & \multicolumn{5}{|c|}{ Horizontal angle $\left[{ }^{\circ}\right]$} \\
\hline Vertical angle $\left[{ }^{\circ}\right] \downarrow$ & $-10 \mathrm{H}$ & $-5 \mathrm{H}$ & $0 \mathrm{H}$ & $5 \mathrm{H}$ & $10 \mathrm{H}$ \\
\hline $0 \mathrm{~V}$ & 0.6 & 0.7 & 0.8 & 0.7 & 0.6 \\
\hline$-1 \mathrm{~V}$ & 0.6 & 0.7 & 0.8 & 0.7 & 0.6 \\
\hline Measured luminance $\left[\mathrm{cd} / \mathrm{m}^{2}\right]$ & \multicolumn{5}{|c|}{ Horizontal angle $\left[{ }^{\circ}\right]$} \\
\hline Vertical angle $\left[{ }^{\circ}\right] \downarrow$ & $-10 \mathrm{H}$ & $-5 \mathrm{H}$ & $0 \mathrm{H}$ & $5 \mathrm{H}$ & $10 \mathrm{H}$ \\
\hline $0 \mathrm{~V}$ & 6.389 & 6.525 & 7.215 & 6.680 & 6.497 \\
\hline$-1 \mathrm{~V}$ & 6.477 & 6.212 & 7.193 & 6.284 & 6.729 \\
\hline Actual luminance $\left[\mathrm{cd} / \mathrm{m}^{2}\right]$ & \multicolumn{5}{|c|}{ Horizontal angle $\left[{ }^{\circ}\right]$} \\
\hline Vertical angle $\left[{ }^{\circ}\right] \downarrow$ & $-10 \mathrm{H}$ & $-5 \mathrm{H}$ & $0 \mathrm{H}$ & $5 \mathrm{H}$ & $10 \mathrm{H}$ \\
\hline $0 \mathrm{~V}$ & 73.18292 & 74.74074 & 82.64435 & 76.51619 & 74.42001 \\
\hline$-1 \mathrm{~V}$ & 74.19092 & 71.15547 & 82.39235 & 71.98020 & 77.07746 \\
\hline Coefficient of retroreflectivity $\left[\mathrm{cd} / \mathrm{lx} / \mathrm{m}^{2}\right]$ & \multicolumn{5}{|c|}{ Horizontal angle $\left[{ }^{\circ}\right]$} \\
\hline Vertical angle $\left[{ }^{\circ}\right] \downarrow$ & $-10 \mathrm{H}$ & $-5 \mathrm{H}$ & $0 \mathrm{H}$ & $5 \mathrm{H}$ & $10 \mathrm{H}$ \\
\hline $0 \mathrm{~V}$ & 121.9715 & 106.7725 & 103.3054 & 109.3088 & 124.0333 \\
\hline$-1 \mathrm{~V}$ & 123.6515 & 101.6507 & 102.9904 & 102.8289 & 128.4624 \\
\hline Headlight intensity [cd] & \multicolumn{5}{|c|}{ Horizontal angle $\left[{ }^{\circ}\right]$} \\
\hline Vertical angle $\left[{ }^{\circ}\right] \downarrow$ & $-10 \mathrm{H}$ & $-5 \mathrm{H}$ & $0 \mathrm{H}$ & $5 \mathrm{H}$ & $10 \mathrm{H}$ \\
\hline $0 \mathrm{~V}$ & 1346 & 2186 & 17660 & 9434 & 2240 \\
\hline$-1 \mathrm{~V}$ & 6124 & 10612 & 37804 & 19796 & 5602 \\
\hline Headlight illuminance $[\mathrm{lx}]$ & \multicolumn{5}{|c|}{ Horizontal angle $\left[{ }^{\circ}\right]$} \\
\hline Vertical angle $\left[{ }^{\circ}\right] \downarrow$ & $-10 \mathrm{H}$ & $-5 \mathrm{H}$ & $0 \mathrm{H}$ & $5 \mathrm{H}$ & $10 \mathrm{H}$ \\
\hline $0 \mathrm{~V}$ & 0.1346 & 0.2186 & 1.766 & 0.9434 & 0.2240 \\
\hline$-1 \mathrm{~V}$ & 0.6124 & 1.0612 & 3.7804 & 1.9796 & 0.5602 \\
\hline RPM luminance $\left[\mathrm{cd} / \mathrm{m}^{2}\right]$ & \multicolumn{5}{|c|}{ Horizontal angle $\left[{ }^{\circ}\right]$} \\
\hline Vertical angle $\left[^{\circ}\right] \downarrow$ & $-10 \mathrm{H}$ & $-5 \mathrm{H}$ & $0 \mathrm{H}$ & $5 \mathrm{H}$ & $10 \mathrm{H}$ \\
\hline $0 \mathrm{~V}$ & 16.42 & 23.34 & 182.44 & 103.12 & 27.78 \\
\hline$-1 \mathrm{~V}$ & 75.72 & 107.87 & 389.35 & 203.56 & 71.96 \\
\hline RVP value & \multicolumn{5}{|c|}{ Horizontal angle $\left[{ }^{\circ}\right]$} \\
\hline Vertical angle $\left[{ }^{\circ}\right] \downarrow$ & $-10 \mathrm{H}$ & $-5 \mathrm{H}$ & $0 \mathrm{H}$ & $5 \mathrm{H}$ & $10 \mathrm{H}$ \\
\hline $0 \mathrm{~V}$ & 0.995 & 1.000 & 1.022 & 1.016 & 1.002 \\
\hline$-1 \mathrm{~V}$ & 1.013 & 1.017 & 1.029 & 1.023 & 1.013 \\
\hline
\end{tabular}

Figure 10 shows how RVP values for each of the RPMs change as a function of viewing distance between 100 and $400 \mathrm{~m}$. (For ease of viewing, the data in Figure 10 are segregated by manufacturer.) The plateau characteristic of visual performance that has been discussed previously is evident for all RPMs. The RVP values change very little as distance increases until the threshold is approached, beyond which visual performance decreases precipitously, first for the RPMs with lower reflectances (i.e., blue and red) and then for those with higher reflectances (i.e., yellow and white). It can be seen that the RPMs that had higher luminances at $100 \mathrm{~m}$ (Figure 9) would be expected to remain visible at substantially longer distances than those with lower luminances. For example, the white RPM from Manufacturer A essentially disappears at a distance of $396 \mathrm{~m}$ while the blue RPM of the same type disappears at a distance of $209 \mathrm{~m}$.
Figures 11 and 12 show similar curves as in Figure 10, but for the wet reflective pavement marking tape samples and for the barrier-mounted reflective delineator samples, respectively. These figures also illustrate the plateau characteristic of visual performance as the viewing distance is increased from 100 to $400 \mathrm{~m}$.

\section{Conclusions}

The laboratory measurement results and subsequent analyses of representative roadway luminances and visual performance quantities that could be expected under real-world headlight illumination conditions converge to demonstrate that RPMs and alternatives such as wet reflective pavement marking tape and barrier-mounted reflective delineators can be highly visible elements along the nighttime roadway environment. Although the pho- 
a)

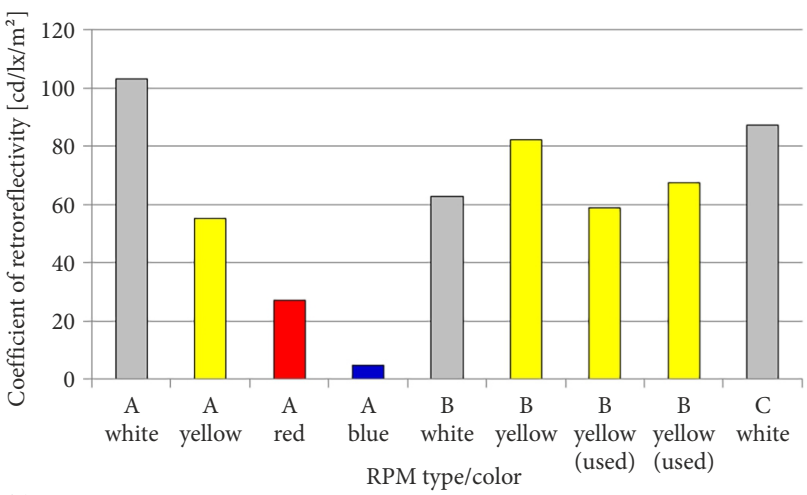

b)

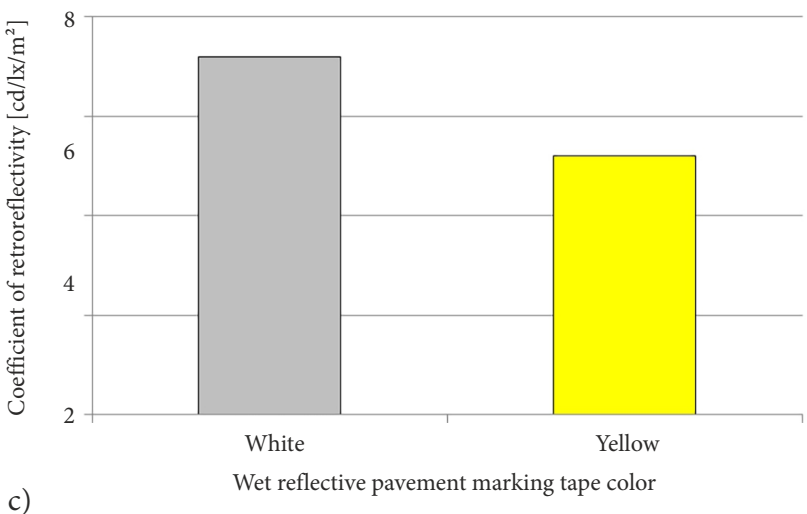

c)

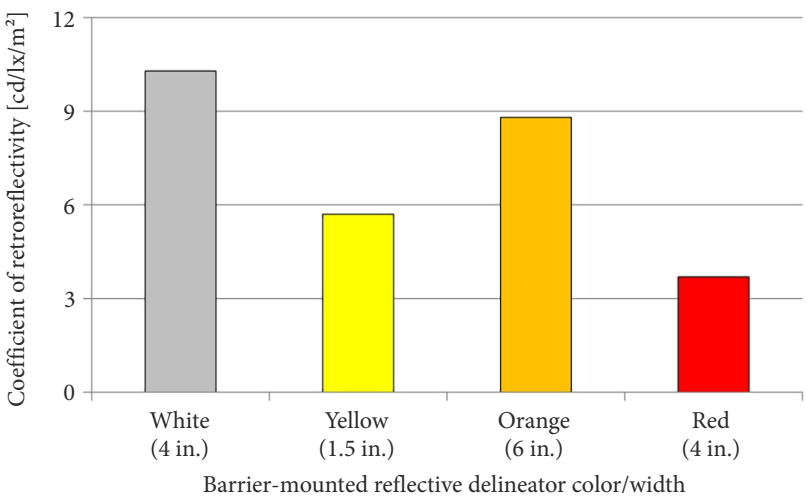

Figure 7. Coefficients of retroreflectivity $\left[\mathrm{cd} / \mathrm{lx} / \mathrm{m}^{2}\right]$ for: $\mathrm{a}$ - RPMs; $\mathrm{b}$ - wet reflective pavement marking tape; $\mathrm{c}$ - barrier-mounted reflective delineators
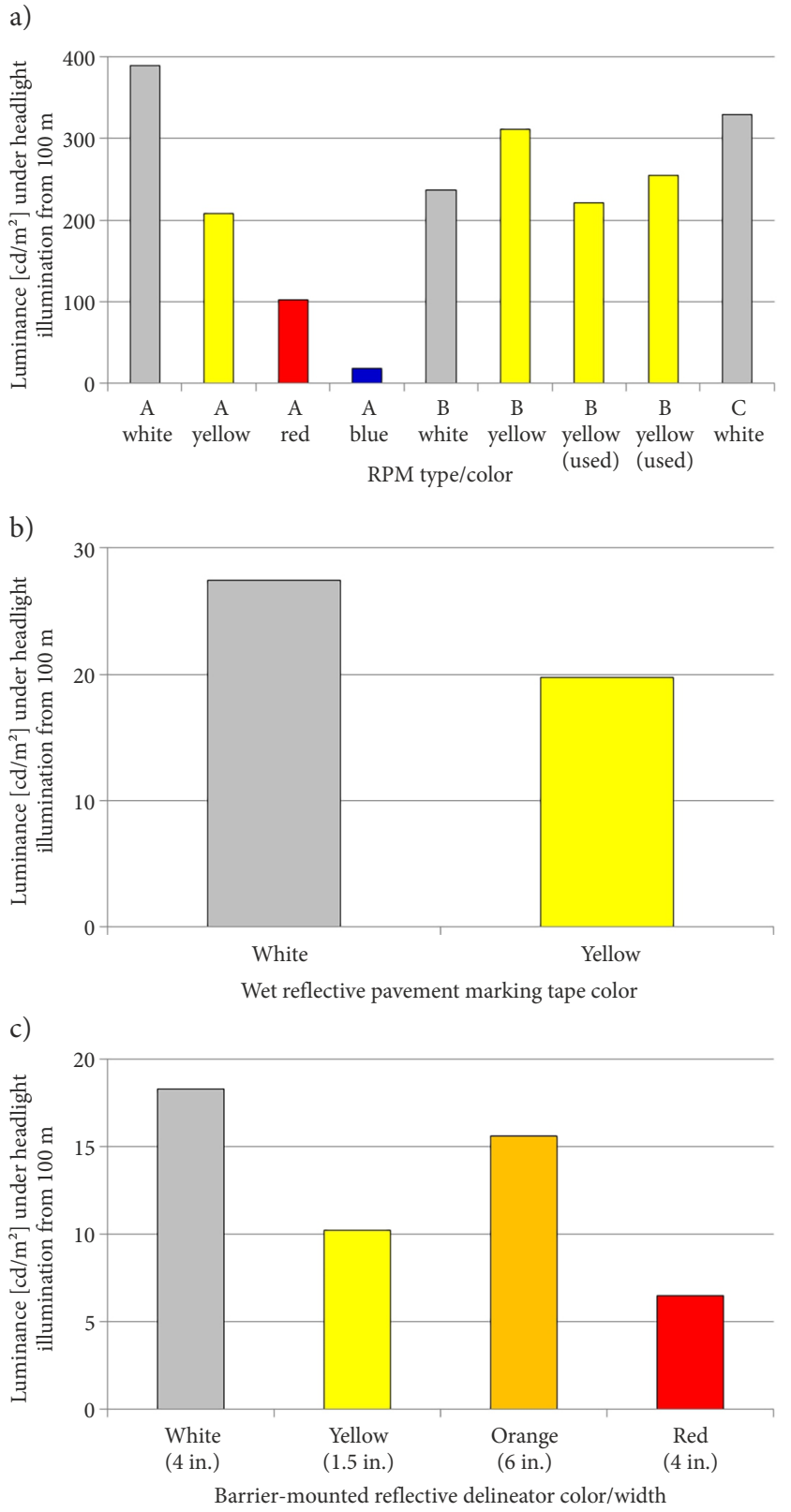

Figure 8. Luminances $\left[\mathrm{cd} / \mathrm{m}^{2}\right]$ under headlight illumination from 100 m away for: $\mathrm{a}$ - RPMs; $\mathrm{b}$ - wet reflective pavement marking tape; $\mathrm{c}$ - barrier-mounted reflective delineators

is not known, however, to what extent these values are representative of what can be found in the field, nor is it known exactly how old the used RPMs were.

Although all of the devices measured resulted in very high visual performance for a viewing distance of $100 \mathrm{~m}$ (i.e., RVP values $\approx$ one; Figure 9), differences among their luminances resulted in larger differences in the threshold visibility distance at which the resulting RVP values reached zero (Figures 10-12), and these threshold visibility differences might have practical implications for driving safety when large preview distances for assessing roadway geometries and configurations are needed. Of course, further data are needed to assess whether these greater preview distances would indeed reduce nighttime crashes. which corresponds to $3.7 \mathrm{~s}$ of driving time at $60 \mathrm{mph}$. It 

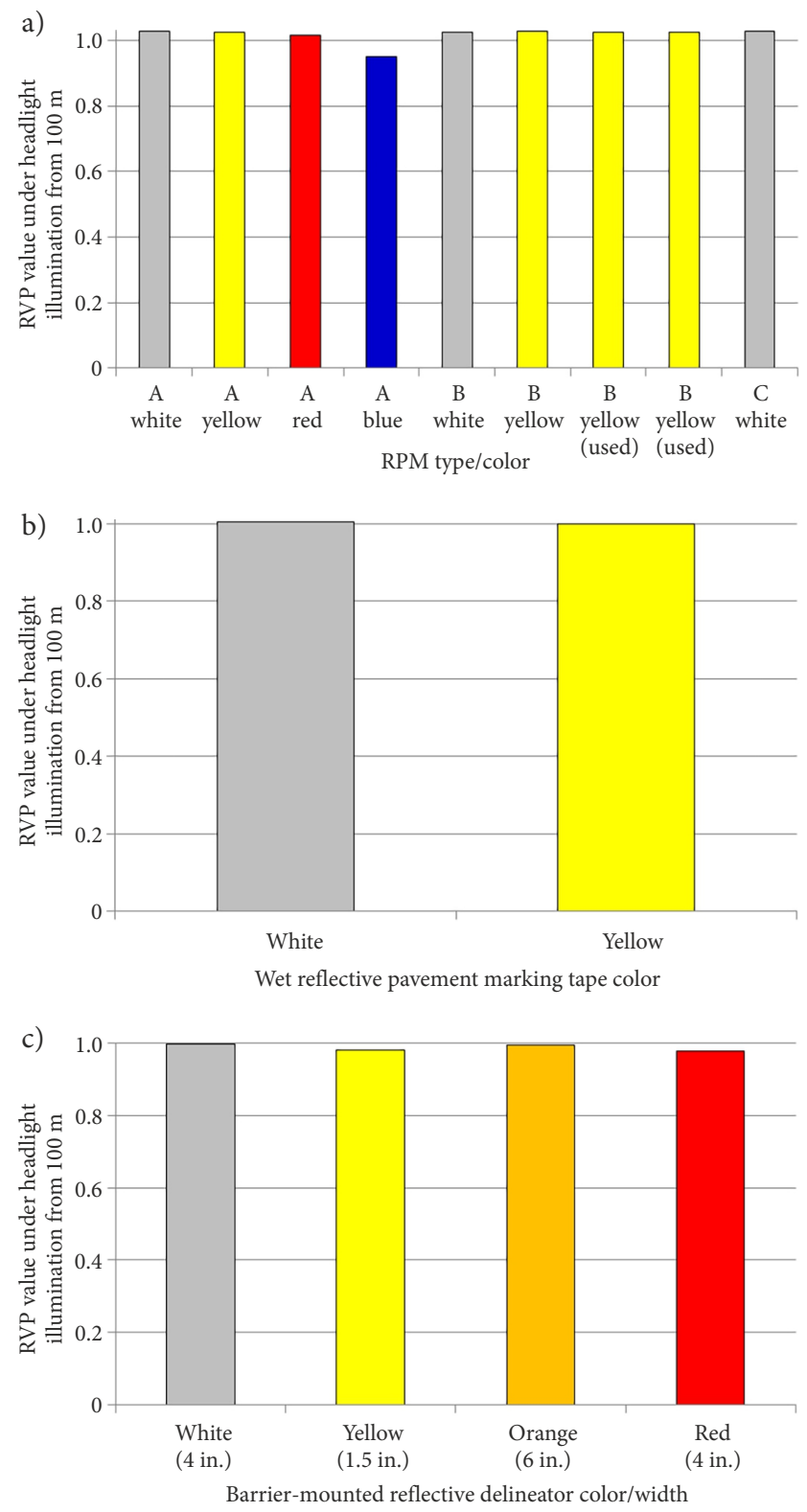

Figure 9. RVP values under headlight illumination from $100 \mathrm{~m}$ away for: $\mathrm{a}$ - RPMs; $\mathrm{b}$ - wet reflective pavement marking tape; $c$ - barrier-mounted reflective delineators

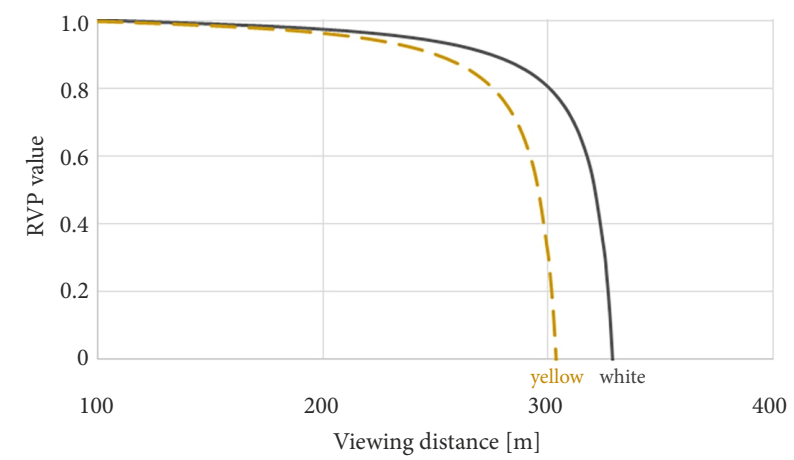

Figure 11. RVP values for each wet reflective pavement marking tape color, as a function of viewing distance

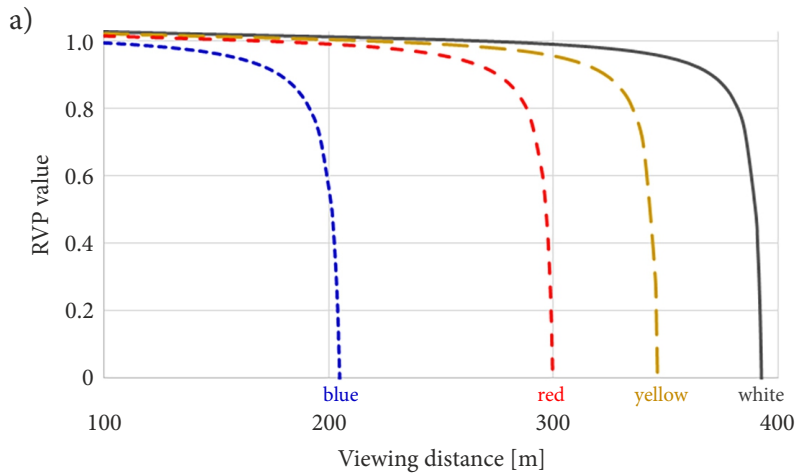

b)

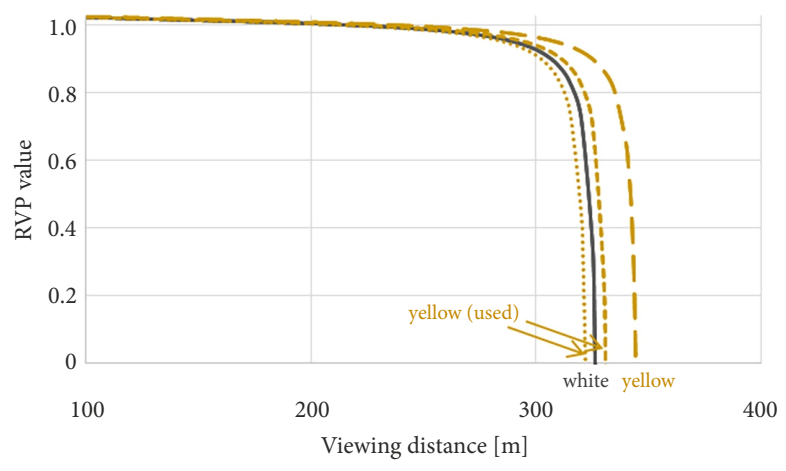

c)

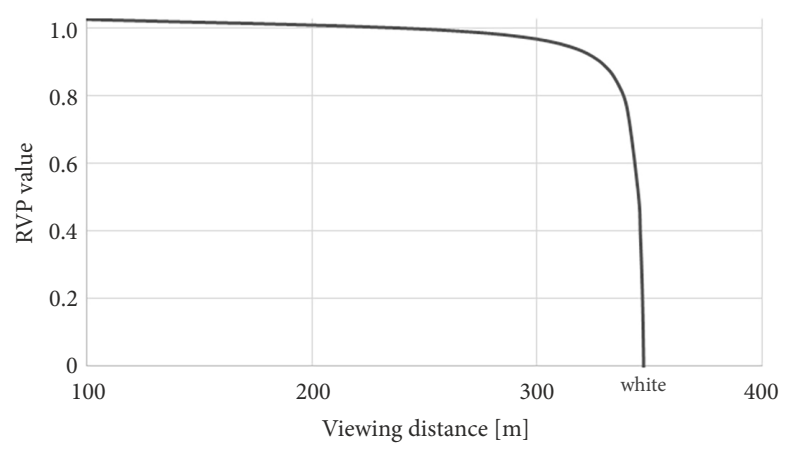

Figure 10. RVP values for each RPM type and color, as a function of viewing distance: a - Manufacturer A; b - Manufacturer B; c - Manufacturer C

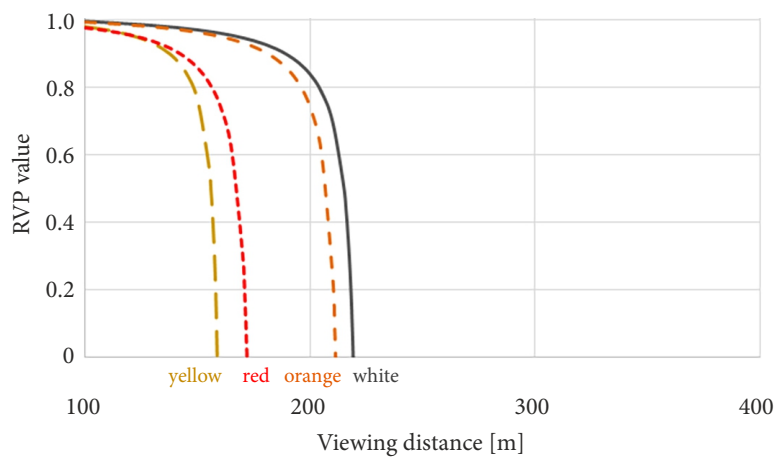

Figure 12. RVP values for each barrier-mounted reflective delineator color, as a function of viewing distance 
Another factor not addressed by these analyses is the spacing or degree of continuous visual information needed to provide useful delineation. For example, although the barrier-mounted reflective delineators had somewhat lower RVP values than the RPMs tested in this study, they are meant to be used in more continuous configurations (Haas 2004), similar to the wet reflective pavement marking tape. In a study of airfield delineation, Bullough and Skinner (2014) evaluated the spacing of simulated taxiway and runway lights and found that relative to lights placed $60 \mathrm{~m}$ apart, spacings of $30 \mathrm{~m}$ and less (including entirely continuous delineation) resulted in faster visual acquisition times. These data would require validation in the roadway context, but suggest that more continuous roadway delineation would be advantageous.

\section{Acknowledgements}

The authors acknowledge the NJDOT for sponsoring this work. Mamun Rashid served as project manager, and members of the technical panel for this project contributed useful advice.

Sample devices were provided by $3 \mathrm{M}$, Ennis Flint and NJDOT.

The authors also wish to acknowledge Juan Carlos Ojeda Alcala, Chris Barretts, Stephen Bennett, Jerry Britt, Camille Crichton-Summers, Stephen Gainer, Vasudevan Ganarajan, Amanda Gendek, Mohsen Jafari, Shan Jiang, Gary Leach, Klyne McCarty, Angelo Mendola, Arati Patel, Leah Picone, Steven Rhyner, Pragna Shah, Eileen Sheehy, Christina Thomas, Liwen Tian, David Villani, Matt Wilding and Andrew Zeleznock for helpful assistance to this project.

\section{Author contributions}

John D. Bullough and Xiang Liu conceived the study. John D. Bullough led the measurement and data analysis and wrote the initial draft of the paper.

John D. Bullough and Xiang Liu were responsible for data interpretation.

\section{Funding}

This work was supported by the NJDOT under Task Order No 328 to Rutgers University (United States).

\section{Disclosure statement}

The authors declare that they have no competing financial, professional, or personal interests from other parties.

\section{References}

ASTM D4383-18. Standard Specification for Plowable, Raised Retroreflective Pavement Markers.
Bahar, G.; Mollett, C.; Persaud, B.; Lyon, C.; Smiley, A.; Smahel, T.; McGee, H. 2004. Safety Evaluation of Permanent Raised Pavement Markers. National Cooperative Highway Research Program (NCHRP) Report 518. Transportation Research Board, Washington, DC US. 69 p. https://doi.org/10.17226/13724

Bhise, V. D.; Farber, E. I.; Saunby, C. S.; Troell, G. M.; Walunas, J. B.; Bernstein, A. 1977. Modeling vision with headlights in a systems context, SAE Technical Paper 770238. https://doi.org/10.4271/770238

Bullough, J. D.; Donnell, E. T.; Rea, M. S. 2013. To illuminate or not to illuminate: roadway lighting as it affects traffic safety at intersections, Accident Analysis \& Prevention 53: 65-77. https://doi.org/10.1016/j.aap.2012.12.029

Bullough, J. D.; Radetsky, L. C. 2014. Roadway lighting, relative visual performance and safety, in Proceedings of the Illuminating Engineering Society Annual Conference 2014, 2-4 November 2014, Pittsburgh, Pennsylvania, US, 203-207.

Bullough, J. D.; Skinner, N. P. 2014. Can linear light sources be beneficial to pilots?, in 2014 FAA Worldwide Airport Technology Transfer Conference: Innovations in Airport Safety and Pavement Technologies, 5-7 August 2014, Galloway, NJ, US, 1-13.

Bullough, J. D.; Skinner, N. P.; O'Rourke, C. P. 2008. Evaluation of New Reflective Materials for Overhead Highway Signage. Research Study No. C-05-08. New York State Department of Transportation (NYSDOT), Albany, NY, US. 52 p.

FHWA. 2011. Our Nation's Highways: 2011. Federal Highway Administration (FHWA), Washington, DC, US. 64 p. Available from Internet:

https://www.fhwa.dot.gov/policyinformation/pubs/hf/pl11028

Griffin, L. I. 1989. Using the Before-and-After Design with Yoked Comparisons to Estimate the Effectiveness of Accident Countermeasures Implemented at Multiple Treatment Locations. Texas Transportation Institute, Texas A\&M University, US. 24 p. Available from Internet: https://tti.tamu.edu/documents/TTI-1989-ID4057.pdf

Haas, K. 2004. Evaluation of $3 M^{\mathrm{Tm}}$ Scotchlite ${ }^{\mathrm{TT}}$ Linear Delineation System. Final Report SPR 306-291. Oregon Department of Transportation, Salem, OR, US. 34 p. Available from Internet: https://digital.osl.state.or.us/islandora/object/osl:9887

Hammond, J. L.; Wegmann, F. J. 2001. Daytime effects of raised pavement markers on horizontal curves, ITE Journal 71(8): $38-41$.

He, Y.; Rea, M.; Bierman, A.; Bullough, J. 1997. Evaluating light source efficacy under mesopic conditions using reaction times, Journal of the Illuminating Engineering Society 26(1): 125-138. https://doi.org/10.1080/00994480.1997.10748173

Horberry, T.; Anderson, J.; Regan; M. A. 2006. The possible safety benefits of enhanced road markings: a driving simulator evaluation, Transportation Research Part F: Traffic Psychology and Behaviour 9(1): 77-87.

https://doi.org/10.1016/j.trf.2005.09.002

IES. 2014. Roadway Lighting RP-8. Illuminating Engineering Society (IES), New York, NY, US.

Krammes, R. A.; Tyer, K. D. 1991. Post-mounted delineators and raised pavement markers: their effect on vehicle operations at horizontal curves on two-lane rural highways, Transportation Research Record: Journal of the Transportation Research Board 1324: 59-71.

Lay, M. G. 2009. Handbook of Road Technology. CRC Press. 944 p. 
Liang, G.-H.; Zhang, D.; Du, S.-B.; Yin, Y.-J.; Li, R.; Shi, B.-R. 2018. Effects of the installation angle of raised pavement markers on a horizontal curve section on the line of sight induction performance, Mathematical Problems in Engineering 2018: 3541784. https://doi.org/10.1155/2018/3541784

Lu, Q.; Guo, L.; Yu, B. 2016. Design improvements of retroreflective raised pavement markers based on quantification of their physical properties, in Transportation Research Board 95th Annual Meeting, 10-14 January 2016, Washington, DC, US. 1-17.

Lyon, C.; Persaud, B.; Eccles, K. 2015. Safety Evaluation of WetReflective Pavement Markings. Report FHWA-HRT-15-065. US Department of Transportation, Washington, DC, US. 54 p. Available from Internet: https://www.fhwa.dot.gov/publications/research/safety/15065/15065.pdf

Niessner, C. W. 1984. Raised Pavement Markers at Hazardous Locations. Report FHWA-TS-84-215. Federal Highway Administration (FHWA), Washington, DC, US. 78 p.

NYSDOT. 1997. Raised Reflectorized Snowplowable Pavement Markers. New York State Department of Transportation (NYSDOT), Albany, NY, US. 8 p. Available from Internet: https://www.dot.ny.gov/spec-repository-us/685.03100018.pdf

Pike, A. M. 2017. Laboratory-based retroreflectivity assessment of raised retroreflective pavement markers, Transportation Research Record: Journal of the Transportation Research Board 2612: 113-120. https://doi.org/10.3141/2612-13

Rea, M. S. (Ed.). 2000. IESNA Lighting Handbook: Reference \& Application. Illuminating Engineering Society of North America. 1000 p.

Rea, M. S., Ouellette, M. J. 1991. Relative visual performance: a basis for application, Lighting Research \& Technology 23(3): 135-144. https://doi.org/10.1177/096032719102300301

Schoettle, B.; Sivak, M.; Flannagan, M. J.; Kosmatka, W. J. 2004. A Market-Weighted Description of Low-Beam Headlighting Patterns in the U.S.: 2004. Report No UMTRI-2004-23. University of Michigan, US. 18 p. Available from Internet: https:// deepblue.lib.umich.edu/bitstream/handle/2027.42/55198/ UMTRI-2004-23.pdf

Zador, P.; Stein, H. S.; Wright, P.; Hall; J. 1987. Effects of chevrons, post-mounted delineators, and raised pavement markers on driver behavior at roadway curves, Transportation Research Record: Journal of the Transportation Research Board 1114: 1-10.

Zador, P. L.; Wright, P. H.; Karpf, R. S. 1982. Effect of Pavement Markers on Nighttime Crashes in Georgia. Project No E-20-617. Insurance Institute for Highway Safety, Washington, DC, US. $21 \mathrm{p}$. 